\title{
Manuel Querino e a escrita da história no Brasil republicano
}

\section{Manuel Querino and the writing of history in republican Brazil}

DOI: $10.46814 /$ lajdv3n3-006

Recebimento dos originais: 23/12/2020

Aceitação para publicação: 26/02/2021

\section{Paulo Marcos Pereira}

Mestre em História pelo programa de Pós-graduação em História Regional e Local da Universidade do Estado da Bahia - UNEB

Instituição de atuação atual: Secretaria de Educação do Estado da Bahia e Universidade do Estado da Bahia - UNEB

Endereço: Rua Ney Pina Leite, N 324, Tamboril, Seabra/BA. CEP.: 46900-000, Brasil. E-mail: paulomarcospereira@gmail.com

\section{RESUMO}

O presente trabalho é uma reflexão sobre a escrita da História do Brasil nas primeiras décadas do século XX, tendo como foco a produção historiográfica do intelectual negro Manuel Raymundo Querino, reconhecido como o primeiro historiador negro a se dedicar a escrita da história do Brasil. Querino era baiano e viveu entre os anos de 1851 e 1923. Exerceu inúmeras funções e estabeleceu diversas relações com variados tipos de sujeitos sociais. Formado em desenho pela Escola de Belas Artes, Querino foi funcionário público, vereador, professor, esteve envolvido com o movimento operário, participou de irmandades e foi um dos membros fundadores do Instituto Geográfico Histórico da Bahia - IGHB. Em sua obra apresenta uma singular proposta de escrita da história do Brasil. No seu texto A Bahia de outrora, de 1909 faz críticas às mudanças promovidas pela implantação da República que não beneficia a diversos agentes sociais que foram marginalizados como os africanos e seus descendentes. No texto O colono preto como fator de civilização brasileira, escrito em 1918, defende que a formação da sociedade brasileira resulta principalmente do trabalho do "colono preto", modo como se refere aos africanos escravizados no Brasil. Desse modo, defendemos a inserção de Manuel Querino entre os escritores de seu tempo como referência a História da Historiografia Brasileira.

Palavras-chave: Manuel Querino. Africano colonizador. Escrita da história do Brasil. História da historiografia brasileira.

\begin{abstract}
The present work is a reflection on the writing of Brazilian History in the first decades of the 20th century, focusing on the historiographical production of the black intellectual Manuel Raymundo Querino, recognized as the first black historian to dedicate himself to the writing of Brazilian history. Querino was from Bahia, Brazil, and lived from 1851 to 1923 . He held numerous positions and established several relationships with various types of social subjects. A graduate in drawing from the School of Fine Arts, Querino was a civil servant, councilman, teacher, was involved in the labor movement, participated in brotherhoods, and was one of the founding members of the Instituto Geográfico Histórico da Bahia (IGHB). In his work, he presents a unique proposal for writing the history of Brazil. In his text A Bahia de outrora, from 1909, he criticizes the changes promoted by the implementation of the Republic, which did not benefit the various social agents who were marginalized, such as the Africans and their descendants. In the text The black settler as a factor in Brazilian civilization, written in 1918, he defends that the formation of Brazilian society results mainly from the work of the "black settler", the way he refers to the enslaved Africans in Brazil. Thus, we
\end{abstract}


defend the insertion of Manuel Querino among the writers of his time as a reference to the History of Brazilian Historiography.

Keywords: Manuel Querino. African colonizer. Writing of the history of Brazil. History of Brazilian historiography.

\section{INTRODUÇÃO}

Manuel Raymundo Querino é reconhecido por alguns estudiosos de sua obra como um dos primeiros historiadores negros a se dedicar a escrita da história do Brasil ${ }^{2}$, um dos principais focos de sua escrita foram as sobrevivências e práticas culturais africanas, o que lhe redeu uma vinculação a etnografia, antropologia, estudos afro-brasileiros e história. Essa visão sobre a obra e figura de Manuel Querino contrasta-se com aquelas apresentadas por autores que o leram na década de 1930 e efetuaram críticas, cobrando-lhe dentre outras coisas rigor metodológico. Além disso, estabeleceram comparações entre Querino a Nina Rodrigues, seu contemporâneo, médico legista, professor da Faculdade de Medicina da Bahia e um dos principais nomes dentre os estudiosos percussores dos estudos sobre os negros no Brasil. Querino dividiu esse pioneirismo com Nina Rodrigues. Essa relação, estabelecida entre ambos estudiosos, efetuadas por Arthur Ramos e Edson Carneiro forjou uma imagem desse intelectual negro como um "pesquisador honesto", "modesto professor", mas sem a grandiosidade da intelectualidade de Nina Rodrigues. Com isso, criou-se parâmetros de leituras das obras de Querino que situavam em um lugar específico no universo da intelectualidade de seu tempo. Esses parâmetros influenciaram leituras posteriores. Mas esta imagem esta sendo desconstruída nos dias atuais a partir de algumas pesquisas sobre a vida e obra de Manuel Querino.

Assim, imagem de Querino como historiador que se hoje torna-se evidente ao ler sua obra, trata-se de um esforço de alguns pesquisadores e estudiosos de mostrar as contribuições de Querino à sociedade acadêmica, de forma que essa possa conhecê-lo. Nesse sentido a dimensão historiográfica da produção intelectual de Querino é uma questão em aberto na sua história de vida. Este sujeito reuniu várias atribuições ao longo de sua trajetória. Foi artista (diplomado), jornalista, professor, político, historiador. Viveu a saga de um negro livre que se fez intelectual, que buscou ocupar vários espaços, construir várias relações sociais com vários tipos de sujeitos sociais ${ }^{1}$, numa sociedade escravista. Esta sociedade passava por transformações marcantes de sua história. Querino viveu entre a segunda metade do século XIX e início do XX. Em função disso, experimentou a guerra do Paraguai, o fim da escravatura, proclamação da República, e morreu um ano depois da Semana de Arte

\footnotetext{
${ }^{1}$ LEAL, Maria das Graças de Andrade. Manuel Querino entre letras e lutas - Bahia: 1851-1923. São Paulo: Annablume, 2009.
} 
Moderna. Em sua trajetória manteve contatos com pessoas importantes da sociedade baiana, como políticos e intelectuais e com pessoas simples, trabalhadores, negros livres, libertos e artistas. Nesse percurso, transitando no âmbito da intelectualidade se posicionou em favor desses últimos. Uma das grandes marcas de sua versão de escrita da história do Brasil foi a defesa da participação dos africanos nos processos de constituição da sociedade brasileira, na condição de agentes importantes, tanto para a colonização, quanto para a civilização desta. Desse modo, o nosso objetivo nessa reflexão é analisar textos de Querino, identificando sua contribuição a história do Brasil e os diálogos que construiu com historiadores de seu tempo a partir de dois de seus textos: A raça africana e seus costumes na Bahia e $O$ colono preto como fator de civilização.

Manuel Raimundo Querino nasceu em 1851 em Santo Amaro da purificação, um ano depois da proibição do tráfico de escravos, contava 37 anos em 1888, ou seja, praticamente metade de sua existência foi durante o sistema escravista. Filho de pais livres ou ex-escravos, teve um destino muito diferente que a maioria dos negros de sua época. Órfão aos cinco anos de idade, em função de uma epidemia de cólera que acometeu muitas pessoas em 1855, inclusive seu pai e sua mãe. Em decorrência disso, Querino passou a residir em Salvador sob a tutela do prof. Manuel Correia Garcia. Foi alfabetizado e aprendeu o ofício de pintor. Isso não acontecia muito na época, segundo alguns autores intrigados com esse fato. "O mais comum é que tivesse sido educado apenas para serviçal". ${ }^{2}$ Sabemos que o professor Manuel Correia Garcia exerceu grande influência na vida de Querino, que tentou seguir seus passos no mundo político e intelectual. Querino participou da Guerra do Paraguai, esteve envolvido com Partido Liberal, trabalhou como pintor-decorador em obras da construção civil, foi estudante Liceu de Artes e Ofícios e diplomou-se Desenhista pela Academia de Belas Artes. Além disso, em sua trajetória esteve envolvido com a criação da Liga Operária Baiana, fundação Partido Operário, foi Conselheiro em duas legislaturas (1891-1892 e 1897-1899) na recém-nascida República, jornalista, pertenceu a várias irmandades de ajuda mútua e foi um dos membros fundadores do Instituto Geográfico e Histórico da Bahia. Seus principais textos foram: As Artes na Bahia escorço de uma contribuição histórica (1909), Artistas Baianos - indicações biográficas (1909), Bailes Pastoris (1914). A Bahia de Outrora - vultos e fatos populares (1916,); a Raça africana

\footnotetext{
2 GUIMARÃES, Antonio Sérgio Alfredo. Manuel Querino e a formação do "pensamento negro " no Brasil, entre 1890 e 1920. Comunicação apresentada no $28^{\circ}$ Encontro Nacional da ANPOCS, em Caxambu, outubro de 2004.

p. 09. Ver também: GLEDHILL, Sabrina. Manuel Querino: um pioneiro no combate ao "racismo científico". Este texto é baseado na dissertação de mestrado da autora, intitulada Afro-Brazilian Studies before 1930: Nineteenth-Century Racial Attitudes and the Work of Five Scholars (1986). p. 46. Disponível em: http://www.brasa.org/Documents/BRASA_IX/Sabrina-Gledhill.pdf. Acesso: 11/08/2014.
} 
e os seus costumes na Bahia (1916), O colono preto como fator de civilização brasileira (1918),

A arte Culinária na Bahia (1928).

A obra, A raça africana e seus costumes na Bahia, foi apresentada por Querino no V Congresso Brasileiro de Geografia em 1916. ${ }^{3}$ Trata-se de um conjunto de textos de que tinham sido publicados em jornais e na revista do Instituo Geográfico Histórico da Bahia. Em 1938 compôs o conjunto de textos de Querino organizados em um livro publicado com o título Costumes africanos no Brasil por Arthur Ramos, que se autodenominava discípulo de Nina Rodrigues. Esse livro em 2010 ganhou sua $3^{\mathrm{a}}$ edição. O prefácio da primeira edição, foi

escrito pelo próprio Arthur Ramos, que por sua vez classificou o texto A raça africana como uma memória. Outros o identificam como estudo etnográfico. Ramos diz concordar com o historiador João Ribeiro que afirmou que este texto era "um dos mais consideráveis que temos sobre a raça africana no Brasil", ${ }^{4}$ mas pondera chamando atenção que "apesar das falhas, algumas de certa gravidade, que tiram a esse trabalho o cunho rigorosamente científico, ele pertence como um dos marcos mais sólido de documentação honesta sobre o negro no Brasil". O texto foi subdividido em vários pequenos tópicos que tratam de um assunto referente a usos e costumes com uma ênfase acentuada nas práticas de religiosidade africana. Tratou de costumes que acreditava serem encontrados nos sertões africanos, modo como se refere ao Níger e ao Congo, de como os recémnascidos eram batizados. Deu notícias de práticas de promessas de casamento entre os filhos de duas mulheres grávidas no mesmo período, do uso da lei de Talião, das formas de captura de sujeitos para serem vendidos como escravos e outros que se vendiam como cativos, do tráfico de escravos efetivado pelos árabes. E depois voltou olhar para o modo como esses africanos foram introduzidos no Brasil e descreveu várias experiências ligadas ao universo religioso africano. Querino listou assuntos e apresentou informações detalhadas, como culto feiticista classificada como atividade religiosa variante do sabeísmo, os orixás como uma apresentação simbólica do santo e vários outros como fazer santo, dar comida a cabeça, cair no santo, despachar santo. No final do texto, na parte titulada indústria Querino tratou da atividade desenvolvida por africanos libertos "não possuindo ofício e não querendo integrar-se aos trabalhos da lavoura, que haviam deixado faziam-se ganhadores" descrevendo um pouco o cotidiano de egressos do cativeiro. Em seguida tratou dos malês em várias partes e numa delas se ocupou da revolta de 1835 no qual afirmou categoricamente

\footnotetext{
${ }^{3}$ Em nota de rodapé a historiadora Maria das Graças de Andrade Leal chama atenção paro fato que esse texto de Querino ter sido o único estudo de conteúdo racial e único trabalho apresentado naquele evento que não trava de temas das áreas de geografia, cartografia, hidrografia, climatologia e outras disciplinas próximas da geografia. LEAL, Maria das Graças. Op. cit. p. 100.

${ }^{4}$ RAMOS, Arthur. Prefácio. In: QUERINO, Manuel Raymundo. Costumes africanos no Brasil. Salvador: Eduneb, 2010.
} 
que não há razão ou fundamento de verdade no fato de atribuir aos africanos malês o levante de 1835 , nesta capital." No geral, o texto é um conjunto de registros de usos e costumes que podem servir de fonte para pesquisas sobre as religiões africanas e afro-brasileiras.

Já o texto $O$ colono preto como fator de civilização brasileira, o principal foco de Querino foi a participação do africano na construção daquilo que compreendia ser a civilização brasileira. O texto está organizado em seis capítulos conectados, a partir de uma narrativa histórica, na qual o autor lançou o olhar em direção ao passado e coletou elementos que o auxiliou a elaborar uma interpretação da sociedade de seu tempo. No primeiro capítulo,

Querino se reportou a ação colonizadora portuguesa nos meados do século XVI. Com base em alguns historiadores contemporâneos desqualificou e criticou essa ação civilizadora dos portugueses. No capítulo seguinte, tratou da chegada dos africanos aqui no Brasil e as habilidades que trouxeram como elementos fundamentais para que a civilização fosse possível. No terceiro, quarto e quinto descreveu de forma processual o modo como aqueles africanos, após sobreviverem à travessia, ao chegar aqui e serem postos em trabalho pesado, reagiram aos castigos e a condição de cativos. Segundo Querino, a primeira reação foi o suicídio. Depois, atacaram e mataram seus senhores, mas ao perceber a pouca funcionalidade dessas ações começaram a criar outras estratégias de resistências como as juntas de alforrias, a fuga e constituição de quilombos. No último capítulo, Querino concluiu defendendo o africano, ou seja, o colono preto, como agente principal da constituição da civilização brasileira. Os africanos teriam influenciado a vida familiar brasileira e deixado vários descendentes notáveis.

\section{A RAÇA AFRICANA E COLONO PRETO COMO: E A ESCRITA DA HISTÓRIA NOS PRIMEIROS ANOS DA REPÚBLICA}

A escrita da história, bem como o perfil do historiador brasileiro da segunda metade do século XIX e início do XX seguiam pelo menos três linhas de trabalhos. Conviviam no Brasil, pelo menos, três formas de se representar o passado: “1) autores e obras na antiga orientação de crônica; 2) cultivo do eruditismo, cujo nome principal foi Varnhagen; 3) autores e obras com nível moderno, de pesquisa intensa, metodologia segura, temática original, elaboração superior". ${ }^{6}$ Nesse último grupo podemos listar os nomes de Capistrano de Abreu, Silvio Romero, Euclides da Cunha, Oliveira Lima, Tobias Barreto, Eduardo Prado, Manoel Bomfim, João Ribeiro, e outros ainda pouco conhecidos como intelectuais vinculados a escrita da história do Brasil como foi o caso de Manuel Querino. Além dessa

\footnotetext{
${ }^{5}$ QUERINO. Manuel Raymundo. A raça africana e seus costumes na Bahia. QUERINO, Manuel Raymundo. Costumes africanos no Brasil. Salvador, Eduneb, 2014. p. 10.

${ }^{6}$ IGLÉSIAS, Francisco. Os historiadores do Brasil: capítulos de historiografia brasileira. Rio de Janeiro: Nova Fronteira; Belo Horizonte: UFMG, IPEA, 2000. p. 94-95.
} 
diversidade de formas de apresentar o passado deve se levar em conta que a própria história estava se definindo enquanto disciplina, com a sistematização de seu estatuto de ciência. E o historiador de profissionalizava, embora esse papel e atividade de escrita da história já existissem no Brasil desde período colonial.

Nessa terceira linha de trabalho, usando termos de Francisco Iglésias, possuem, por sua vez, uma variedade de interpretações do passado colonial brasileiro e de perspectivas da escrita da história do Brasil. Desse grupo, Capistrano de Abreu e João Ribeiro, costumam ser vistos como modelos de historiadores. Muitos se dedicavam a várias atividades e áreas de conhecimento que além de historiadores eram, professores, funcionários públicos, jornalistas, poetas, críticos literários. O que possuíam em comum eram suas preocupações com a escrita da história.

A singularidade da interpretação da escrita da história de Manuel centrava-se em sua defesa e positivação da participação dos africanos na constituição da sociedade brasileira. Esse processo de formação do Brasil despertou o interesse de boa parte da intelectualidade brasileira daquele período. A maioria desses indivíduos via esse processo como resultado da colonização portuguesa e situavam os africanos e indígenas na posição de coadjuvantes. O que se justificava em função da influência que teorias raciais estrangeiras exerciam sobre essas leituras, feitas por Sílvio Romero e Euclides da Cunha, por exemplo.

O Manuel Querino enquanto historiador pode ser identificado em sua própria obra, na qual demonstrou preocupações similares aos intelectuais contemporâneos, vinculados a um lugar de produção do conhecimento histórico, como os institutos históricos e geográficos que se espalharam pelo Brasil depois da criação do Instituto Histórico e Geográfico Brasileiro em 1838. Querino este vinculado ao Instituto Geográfico Histórico da Bahia e foi correspondente do Instituto Histórico do Ceará.

Nos textos, A raça Africana e sues costumes na Bahia e $O$ colono preto como fator de civilização brasileira, podemos identificar elementos que nos ajudam a compreender o pensamento de Querino e a sua relação com alguns brasileiros das primeiras décadas do século da República. E a partir desses dois textos podemos identificar os instrumentos teóricos e metodológicos que usou na sua produção intelectual e percebemos a sua inserção nos debates travados pelos historiadores de seu tempo.

A abordagem dada por Querino à história do foi muito especifica e expressiva. Para Querino o Brasil ou a civilização brasileira era resultado do trabalho africano. Percebemos uma espécie de apologia ao trabalho africano. Querino o elevou a categoria de colonos e conferiu-lhes uma parcela da reponsabilidade pela "construção da civilização brasileira". O que pode ser identificado no título de um de seus textos que apresentou tal abordagem, $O$ colono preto como fator de civilização 
brasileira. Em a raça africana começou a apresentar alguns traços dessa imagem do "africano civilizador". Afreimou categoricamente que,

O africano foi um grande elemento ou o fator maior da prosperidade econômica do país: era o braço ativo e nada se perdia do que ele pudesse produzir. $\mathrm{O}$ seu trabalho incessante e não raro sob o rigor dos açoites tornou-se a fonte da fortuna pública e particular. ${ }^{7}$

Essa ideia foi posta em primeiro plano no texto $O$ colono preto, no qual seguiu essa linha de raciocínio e desenvolveu uma narrativa a partir de um conjunto de argumentos buscando explicar a seu modo qual o papel exercido pelos africanos na formação da sociedade brasileira. Nesse procedimento fica subtendido o desejo de Querino de reivindicar, um melhor tratamento destes africanos e seus descendentes em um contexto marcado por leituras da realidade brasileira com base em teorias raciais. No podemos identificar o militante negro no combate ao racismo.

Antes de apresentar seus argumentos com o intuito de assegurar ao africano o título de principal fator de civilização brasileira, Querino desconstruiu a imagem do colo branco como os principais elementos daquele processo. Se reportou ao início da colonização portuguesa se referindo aos portugueses como "os piores elementos da metrópole" que teriam fracassado com a tentativa de colonizar o índio. A partir desse insucesso

a metrópole mudou o rumo, e, a exemplo de outras nações da Europa, e, de parceria com o árabe, firmou o seu detestável predomínio no celeiro inesgotável que fora o Continente Negro, arrancou dali o braço possante do africano para impulsionar e intensificar a produção de cereais e cana de açúcar e desentranhar do seio da terra o diamante e metais precisos. ${ }^{8}$

$\mathrm{O}$ argumento principal argumento de Querino foi que os africanos quando trazidos para o Brasil na condição de escravo estava "já aparelhado para o trabalho que o esperava aqui, como bom caçador, marinheiro, criador, extrator de sal, abundantes em algumas regiões, minerador de ferro, mercador de marfim, etc." $"$ A ideia chave nessa leitura que fez dos africanos está no trabalho. O trabalho do africano foi a força motriz dentro dos processos que levaram a constituição do Brasil. "Foi com o produto do seu trabalho que tivemos as instituições científicas, letras, artes, comércio, indústria, etc., competindo-lhe, portanto, um lugar de destaque, como fator da civilização brasileira" ${ }^{10}$. E continua

Foi com o produto do seu labor que os ricos senhores puderam manter os filhos nas Universidades européias, e depois nas faculdades de ensino do País, instruindo-os, educando-

\footnotetext{
${ }^{7}$ QUERINO, Manuel Raymundo. O colono preto como fator de civilização brasileira: In QUERINO, Manuel Raymundo. Costumes africanos no Brasil. Salvador, Eduneb, 2010.

${ }^{8}$ QUERINO, Manuel Raymundo. Op. cit., p. 135

${ }^{9}$ Ibidem. p. 137.

${ }^{10}$ Ibidem. p. 151.
} 
os, donde saíram veneráveis sacerdotes, consumados políticos, notáveis cientistas, eméritos literatos, valorosos militares, e todos quantos, ao depois fizeram do Brasil colônia, o Brasil independente, nação culta, poderosa entre os povos civilizados. ${ }^{11}$

O Brasil vivido por Manuel Querino é interpretado por ele como fruto do trabalho escravo do africano. A ideia de trabalho estava atrelada as noções de colonização e civilização. O africano, na condução de escravo, era visto como um simples "máquina do trabalho" por intelectuais contemporâneos de Querino. Este defendia que os cativos filhos do continente negro, na colônia, serviram de "suporte" para que fosse possível, os senhores de escravo mantivessem seus filhos nas universidades europeias, de onde sairiam sacerdotes, militares, políticos, notáveis cientistas que posteriormente transformaram a colônia num pais "independente, nação culta, poderosa entre os povos civilizados”. Com isso, Querino, construía argumentos fortes que para discordar do tratamento reservado aos africanos que aos poucos estavam entrando em extinção e seus descendentes no contexto da emancipação. Por isso que denunciou o que, "entre nós, o elemento português fez do africano e sua descendência a máquina inconsciente do trabalho, um instrumento de produção, sem retribuir- lhe o esforço, antes torturando-o com toda a sorte de vexames. ${ }^{12}$

Assim a dimensão historiográfica da obra de Manuel Querino pode ser identificada na apropriação da obra de vários historiadores e autores de outras áreas, contemporâneos com os quais estabeleceu diálogo, como Melo Morais Filho, Oliveira Lima, Oliveira Martins, João Ribeiro e Rocha Pombo, evocando-os algumas vezes em sua narrativa demonstrando possuir um repertório de leituras. A partir desses autores embasava seus textos, mostrando que não era um autor isolado ou que estivesse forra do universo da intelectualidade de sua época.

Dentre os historiadores citados por Querino devemos destacar Rocha Pombo. Esse autor foi citado nos dois textos em questão. No texto A raça africana e seus costumes na Bahia, Querino se apropriou se utilizou da fala de Rocha Pombo para definir os caminhos que deveria trilhar na pesquisa sobre os usos e costumes dos africanos.

conviria muito, pois, antes da extinção completa da raça africana, no Brasil, e, sobretudo, antes que desapareçam as variedades mais interessantes e menos vulgarmente conhecidas, apanhar dos próprios indivíduos, que as representam, informações que dentro de pouco tempo será impossível ou pelo menos muito difícil de obter. Há, entre os negros transportados da África, indivíduos oriundos de regiões do interior do continente, até onde nenhum viajante conseguiu ainda ir, e que não se acham mencionados em nenhuma relação publicada. Podese ainda distinguir e estudar os tipos diversos, constatar-lhes autenticamente a origem, interrogar os indivíduos sobre suas crenças, suas línguas, seus usos e costumes, e recolher assim da própria boca dos negros, tanto mais facilmente quanto é certo que eles falam a

\footnotetext{
${ }^{11}$ Idem.

12 Ibidem
} 
Com essas palavras Querino respondeu uma pergunta que deve ter feito ao se propor escrever sobre os africanos: como registrar os costumes africanos em vias de desaparecimento? A partir dessa sugestão de Rocha Pombo se esboçava um roteiro pesquisa, um caminho pelo qual teria acesso às informações mais confiáveis a dar conta de registrar atividades, experiências, língua religiosidade, do africano. Esse roteiro divergia da proposta metodológica em voga na escrita da história efetuada pela maioria dos historiadores. Era necessário uso de documentos oficiais para que fosse possível efetuar tal atividade. Porém, nesse caso, a preocupação de Querino era um tipo de pesquisa que documentos oficiais talvez não lhe servissem de fontes. Qual era a alternativa: o testemunho ouvido da boca dos próprios africanos. Ao se utilizar da fala de Rocha Pombo, Querino, apresentou e justiçou os instrumentos metodológicos que usou no seu estudo. E ao fazer isso demonstrava preocupação de dar ao seu texto os elementos próprios da produção intelectual de seu tempo.

Assim, como podemos notar, uma das principais preocupações de Querino esboçada em sua escrita foi com relação ao registro das experiências africanas que acreditava estarem em vias de desaparecimento.

Essa preocupação com o registro das experiências africanas era algo recorrente no pensamento de intelectuais como Sílvio Romero e Nina Rodrigues. Em Africanos no Brasil, Nina Rodrigues reproduz um fragmento do texto Estudos sobre a poesia popular do Brasil de Sílvio Romero, no qual alegava ser uma vergonha para a ciência no Brasil a pouca existência de trabalhos sobre as religiões e línguas africanas. Reclama que enquanto pesquisadores estrangeiros estão se refugiando dezenas de anos no continente africano, somente para estudar uma língua e coligir uns mitos, nós temos o material em casa, que temos a África em nossas cozinhas, como a América em nossas selvas, e a Europa em nossos salões, nada havendo produzido nesse sentido!" 13 A diferença entre Querino e Romero residia na importância que davam ao africano na composição da sociedade brasileira. Romero encarava os africanos como objetos de estudos da ciência, mas não como sujeitos históricos, tal como Querino o fez.

Nas primeiras décadas da República houve uma mobilização por parte das elites dirigentes do país de colocar o Brasil nos trilhos da modernidade, do progresso e no curso das nações civilizadas e as leituras e análises de intelectuais brasileiros viam os egressos do cativeiro como um problema, pois estes não eram compatíveis à nova sociedade que se desejava. Essas análises serviram de base para as elites dirigentes pensassem estratégias políticas para reverter aquele quadro. Um dos procedimentos foi o apagamento dos rastros deixados pela monarquia e escravidão. Nesse contexto, Querino ao interpretar a sociedade brasileira de seu tempo, voltou os olhos ao passado monárquico, colonial e

\footnotetext{
${ }^{13}$ RODRIGUES, Raymundo Nina. Os Africanos no Brasil. 5a ed. São Paulo: Nacional, 1977. p. XV
} 
escravista e descreveu de forma crítica a atuação dos africanos, demonstrando que aquelas atitudes das elites de eram inadequadas e que não havia incompatibilidade entre esses egressos do cativeiro e a civilização. ${ }^{14}$

Portanto, Manuel Querino deu importante contribuição à escrita da História do Brasil nas primeiras décadas do século XX, ao defender a participação dos africanos no processo de formação da sociedade brasileira rompia com a historiografia de sua época. E a partir do diálogo com as obras de historiadores como Rocha Pombo definiu seus os seus instrumentos metodológicos da pesquisa que desenvolvia sobre as experiências dos africanos, a partir do seu próprio depoimento.

\footnotetext{
${ }^{14}$ SANTOS, Flavio Goncalves dos. “Os discursos dos afro-brasileiros face às ideologias raciais na Bahia” 1889-1937. Dissertação (Mestrado em História) Universidade Federal da Bahia. 2001
} 


\section{REFERÊNCIAS}

FREIRE, Luiz Alberto Ribeiro. A história da arte de Manuel Querino. In $19^{\circ}$ Encontro da Associação Nacional de Pesquisadores em Artes Plásticas. "Entre Territórios" - 201 25/09/2010 - CachoeiraBahia Brasil.

GUIMARÃES, Antonio Sérgio Alfredo. Manuel Querino e a formação do "pensamento negro" no Brasil, entre 1890 e 1920. Comunicação apresentada no $28^{\circ}$ Encontro Nacional da ANPOCS, em Caxambu, outubro de 2004.

GLEDHILL, H. Sabrina. Manuel Querino: Um Pioneiro no Combato ao 'Racismo Científico'. 2008. Disponível em: http://pt.scribd.com/doc/138237986/Manuel-Querino-um-pioneiro-no-combate-doracismo-cientifico.

Acesso: dia 13/08/2014.

IGLÉSIAS, Francisco. Os historiadores do Brasil: capítulos de historiografia brasileira. Rio de Janeiro: Nova Fronteira; Belo Horizonte: UFMG, IPEA, 2000.

LEAL, Maria das Graças de Andrade. Manuel Querino entre letras e lutas - Bahia: 1851-1923. São Paulo: Annablume, 2009.

NUNES, Eliane. Manuel Raymundo Querino: o primeiro historiador da arte baiana. Disponível em: http://www.revistaohun.ufba.br/pdf/eliane_nunes.pdf. Acesso: 20/08/2014.

RODRIGUES, Raymundo Nina. Os Africanos no Brasil. 5a ed. São Paulo: Nacional, 1977.

SANTOS, Flavio Goncalves dos. "Os discursos dos afro-brasileiros face às ideologias raciais na Bahia" 1889-1937. Dissertação (Mestrado em História) Universidade Federal da Bahia. 2001 